\title{
Recomendaciones para la cirugía electiva pediátrica segura durante la pandemia COVID-19
}

\author{
Grupo de Trabajo \\ Comité de Anestesia Pediátrica SACH. Maureira V. ${ }^{1,2}$, Ostermann P. ${ }^{3,4}$, Fajardo A. ${ }^{3,5}$ \\ Comité Científico Sociedad Chilena de Cirugía Pediátrica. Paulos A. ${ }^{5-7}$, Campos J. 4,7.8, Puentes M8, 8,10 . \\ Invitadas Comité Anestesia Pediátrica. Ribal A.9,10,11,12, Monsalve M. ${ }^{3,5}$
}

Lista de abreviaturas:

SACH: Sociedad de Anestesiología de Chile.

SCHCP: Sociedad Chilena de Cirugía Pediátrica.

SARS-CoV-2: Coronavirus 2 del síndrome respiratorio agudo grave.

COVID-19: Enfermedad causada por SARS-CoV-2.

MINSAL: Ministerio de Salud de Chile.

RT-PCR: Reacción en cadena de la polimerasa con transcriptasa reversa en tiempo real.

EPP: Equipos de protección personal.

\section{Introducción}

- n relación a la pandemia por coronavirus CO-

E VID-19, las autoridades tomaron medidas restrictivas resguardando los recursos de atención en el caso de un eventual colapso del sistema de salud. Según la evolución de la enfermedad en Chile y cuando la autoridad sanitaria así lo determine, debiera. La evolución de la enfermedad en Chile ha permitido a la autoridad sanitaria plantearse la posibilidad de reiniciar la cirugía electiva necesaria no urgente y reactivar las garantías de oportunidad para los problemas de salud GES1. Esto se ha planteado con el objetivo de dar continuidad de atención a la población, evitar el mayor incremento de las listas de espera y mermar el daño colateral que se puede desencadenar por alteraciones o retraso de acceso a salud de las patologías no COVID-19 que continúan presentándose durante la pandemia y que de no tener un monitoreo sistemático pueden tener un desenlace en aumento de la morbilidad y mortalidad en niños[2].

En la infección por SARS-CoV-2 la población infantil presenta un comportamiento distinto a la de los adultos, ya que si bien todos los niños son susceptibles de contraer la enfermedad, sólo algunos presentan cuadros graves[3]. Los niños se contagian por contacto con familiares directos, siendo la mayoría asintomáticos o oligosintomáticos, por esto tienen un importante rol en la transmisión del virus en la población[4],[5].

La presentación de la enfermedad varía entre cuadros respiratorios leves, hasta cuadros de neumonía grave con síndrome de distrés respiratorio, shock séptico, enfermedad inflamatoria sistémica y falla multi-

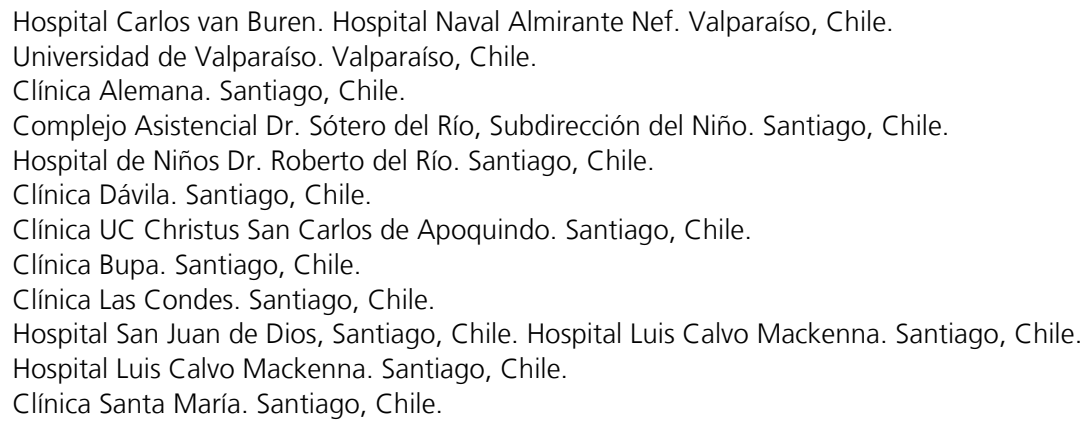

Fecha de Presentación: 3 de junio de 2020

Conflictos de interés: Los autores no presentan conflictos de interés. 
orgánica[3],[5],[6]. A pesar de esto, solo cerca de 5\% de los niños que desarrollan la enfermedad requieren hospitalización, siendo los niños con comorbilidades y los recién nacidos los que presentan mayor riesgo[5].

En Chile, hasta la fecha, los menores de 15 años representan solo el 4,8\% de la población que ha desarrollado la enfermedad[7],[8]. Este porcentaje es mayor que la reportada por otros países, donde 1\%$1,5 \%$ de los pacientes positivos para SARS-CoV-2 se encuentran en la edad pediátrica[5]. Esto puede ser producto de un mayor acceso a la toma de examen diagnóstico o a un diferente criterio epidemiológico de registro.

Respecto a cirugía electiva en contexto de pandemia en otros países, existen reportes de alta morbimortalidad en pacientes adultos, que fueron intervenidos durante el periodo de diseminación comunitaria del virus y con limitados recursos[9]. Los cambios producidos por el estrés quirúrgico y anestésico pareciera que predisponen a infección o exacerbación de la enfermedad.

El diagnóstico y plan de manejo para niños con enfermedades quirúrgicas se ha visto afectado en el periodo de pandemia y el comportamiento de éstos durante la cirugía en este contexto no está todavía claro. Con el fin de evitar consecuencias en el crecimiento, desarrollo y calidad de vida del niño, se debe realizar una planificación multidisciplinaria para así asegurar garantizar un adecuado tratamiento quirúrgico seguro y oportuno[10].

Con este objeto, hemos realizado en forma conjunta entre SACH y SCHCP una guía de recomendaciones para reiniciar la cirugía electiva pediátrica en el contexto de la pandemia COVID-19, enfocándose en las peculiaridades del contexto de la resolución quirúrgica en niños. La implementación de estas recomendaciones deben ser evaluadas y adaptadas a la realidad de cada comunidad e institución, considerando dado que cada localidad cuenta con características propias en términos de recursos y puede estar viviendo una la situaciones epidemiológicas distintas, lo cual determinará las conductas a seguir con respecto a esta materia.

\section{Objetivo general}

Unificar criterios para recomendaciones de atención pediátrica perioperatoria desde las sociedades científicas para dar así lineamientos de cómo enfrentar la atención de pacientes pediátricos que requieran cirugía electiva durante la pandemia por COVID-19 de forma segura.

\section{Objetivos específicos}

Generar una pauta de recomendaciones para el inicio progresivo de la actividad quirúrgica electiva, según la realidad epidemiológica local, asegurando el tratamiento oportuno de los pacientes pediátricos en el contexto de la pandemia COVID-19 y manteniendo la continuidad de la atención a los pacientes COVID-19 (+).

Minimizar el riesgo perioperatorio del paciente pediátrico y el de su familia en cirugía electiva en contexto pandemia COVID-19 y el de su familia. salud.

Minimizar el riesgo en la atención del personal de

\section{Escenario clínico y condición de aplicación}

Esta recomendación va orientada para ser aplicada en el período perioperatorio de pacientes pediátricos, que sean planificados para cirugía electiva en el contexto de la pandemia por COVID-19.

Incluye, el trabajo en conjunto de Jefes de Unidades Quirúrgicas Pediátricas, Jefaturas de Pabellón, Anestesiólogos, Enfermeras e Infectólogos.

Contempla la implementación de estas recomendaciones está asociada al análisis epidemiológico de cada centro quirúrgico y la zona del país donde éste se encuentre.

\section{Metodología}

Búsqueda bibliográfica de recomendaciones de sociedades científicas internacionales y nacionales que atienden pacientes adultos y pediátricos.

Búsqueda bibliográfica de artículos relacionados a la enfermedad según palabras clave: pediátrico, anestesia, cirugía electiva, perioperatorio, test diagnósticos, COVID-19, SARS-CoV-2.

\section{Métodos de consenso}

Puntos de controversia:

Se estableció controversia respecto a:

- Validez de estudios.

- Disponibilidad de estudios pediátricos.

- La aplicabilidad de recomendaciones en pacientes adultos al área pediátrica.

- La aplicabilidad de otras recomendaciones a nuestra realidad nacional.

- Condiciones de aplicabilidad e impacto de estas recomendaciones en los distintos centros del país, dada la distinta realidad a nivel nacional.

- Resolución de controversias. 
- Se aplicaron los siguientes métodos de consenso:

- Representatividad: Todos los autores participaron de la resolución de la controversia.

- Todos los autores dispusieron del mismo nivel de información básica para la toma de decisiones.

\section{Grados de evidencia}

Para esta recomendación se utilizó la evidencia disponible al momento de su redacción. Esta se basa principalmente en recomendaciones clínicas de organizaciones internacionales y nacionales reconocidas, series de casos, artículos de opinión de expertos e informes epidemiológicos.

- Según la evolución de la pandemia y la generación de nueva evidencia, se podrán hacer actualizaciones de este documento.

\section{Consideraciones ético-sociales}

Estas recomendaciones, siguiendo los lineamientos de la SACH y la SCHCP, pretenden ser una herramienta guía para la implementación de cirugía electiva y como apoyo a la práctica anestésica y quirúrgica nacional en pacientes pediátricos en contexto de pandemia COVID-19.

Pretenden ser una ayuda en la toma de decisiones de la praxis anestesiológica y quirúrgica, pero no reemplazan el juicio clínico del tratante y del equipo quirúrgico.

Así estas Sociedades en conjunto, cumplen su responsabilidad ética y científica para aportar antecedentes que puedan ayudar a la atención perioperatoria de los pacientes pediátricos del país, en contexto de cirugía electiva durante pandemia COVID-19.

\section{Desarrollo de recomendaciones}

\section{Consideraciones generales}

La pandemia por COVID-19, obliga a replantear la priorización de los procedimientos quirúrgicos considerando otros aspectos en este nuevo contexto más generales, como las consideraciones éticas en pandemia, seguridad del entorno quirúrgico y anestésico, la preservación y disponibilidad de recursos humanos y materiales, la limitación de contagio del paciente, su entorno familiar cercano y el equipo de salud; para finalmente con el objetivo de disminuir los riesgos perioperatorios del paciente y resolver su patología.

\section{Selección de pacientes}

Objetivo: Realizar un tamizaje de los pacientes aptos para cirugía electiva a través de planear cirugía electiva en pacientes con encuesta epidemiológica negativa al niño paciente y su núcleo cercano; además el paciente y su tutor deben estar asintomáticos y realizar una toma de PCR negativa del paciente.

\section{Recomendamos:}

2.1. Seleccionar pacientes sin factores de riesgo de mayor morbimortalidad por COVID-19.

Algunos factores de riesgo más relevantes son inmunosupresión, obesidad, asma, cardiopatías o menores de 1 año de edad[11].

2.2. Búsqueda activa de pacientes y sus contactos, con sospecha o positivos para SARS-CoV-2.

Dado que la morbimortalidad aumenta al operar pacientes en etapa de incubación o positivos para COVID-19[9], se recomienda:

2.2.1. Realizar encuesta clínica epidemiológica al paciente, tutor y su círculo cercano de contactos, para identificar casos sospechosos, probables o confirmados por COVID-19[8],[12],[13] (Anexo 1).

Debe ser realizada en distintos momentos del proceso de selección y al ingresar al centro quirúrgico.

Debe ser hecha por un profesional de salud, no por personal administrativo.

Debe quedar registrada en la ficha del paciente.

Ante una encuesta positiva (tener una respuesta positiva del cuestionario), que determine sospecha de infección o confirmación de ésta, la cirugía debe ser postergada al menos por 14 días.

2.2.2. Realizar test diagnóstico de RT-PCR al paciente[13],[14],[15],[16],[17],,[18],[19],[20].

Se debe realizar idealmente a las 24 o 48 horas antes del procedimiento, aceptándose incluso hasta 72 horas.

No realizar test al tutor, dada la baja disponibilidad de estos en etapa de pandemia COVID-19.

2.3. Aislamiento preventivo.

El período de incubación de la enfermedad va de 2 a 14 días, con un promedio de 5,5 días. El 97,5\% de los síntomas aparece entre los 11 a 12 días del contagio[16].

2.3.1. Indicar aislamiento preventivo idealmente 14 días, y por un mínimo de 7 días al niño y su tutor[4],,[12],[13].

El período de incubación de la enfermedad va de 2 a 14 días, con un promedio de 5,5 días. El $97,5 \%$ de los síntomas aparece entre los 11 a 12 días del contagio[16].

Dentro de lo posible, se recomienda aislamiento a 
todo el núcleo cercano que vive con el niño o mantener áreas separadas dentro del domicilio para lograr un aislamiento efectivo.

Durante este período se recomienda que el niño no asista al colegio o a espacios públicos.

Las consultas médicas y exámenes preoperatorios, deben ser tomadas idealmente antes del aislamiento.

Durante este período se debe tomar la RT-PCR (24 a 72 horas previo a la cirugía), la cual debe ser idealmente realizada en horario con poca afluencia de público y con las medidas de aislamiento de contacto y gotitas para el niño y su tutor. Posterior a esto deben mantenerse en aislamiento preventivo.

\section{Criterios quirúrgicos}

\section{Recomendamos}

3.1. Realizar categorización y priorización de pacientes[18].

Se debe realizar un análisis para seleccionar los pacientes que podrán realizarse cirugía electiva en pandemia. En la actualidad, para la población adulta, existe una recomendación para categorización a través del MeNTS SCO$\mathrm{RE}[21]$, que incluye características del procedimiento, paciente y patología.

La Sociedad Norteamericana de Cirujanos propone una lista de cirugías pediátricas extensa e integral que pueden servir como orintación base para la categorización de cirugías en nuestra población en el caso de plantearse el reinicio de las cirugías electivas[22]. Recientemente, también se ha realizado una modificación del sistema MeNTS[21] a población pediátrica, llamado pMeNTS para priorizar procedimientos quirúrgicos en niños.

La elección de sistemas de categorización a utilizar por cada institución, deben ser adaptados según su realidad local, que podría ser adaptado a instituciones locales. cuando éstos sean iniciados[23].

Además, de la selección del tipo de cirugías, debe considerarse un plazo de realización con el objeto de obtener los mejores resultados. En la población pediátrica las cirugías programables pueden ser aplazadas por un tiempo determinado ya que se debe considerar el reinicio diligente en la medida que se cumplan las condiciones de seguridad para el paciente, dado que, si bien en muchos casos no se pone en riesgo la salud de éste, la postergación de una cirugía puede traer consecuencias en el crecimiento y desarrollo del niño[24].
Además, en el análisis de la selección de cirugías a priorizar debe considerarse que existen procedimientos que obtienen mejores resultados al ser realizados en un determinado plazo.

3.1.1. Priorizar cirugías ambulatorias.

En la primera etapa de programación, se podría privilegiar cirugías ambulatorias o con estadía hospitalaria hasta un día de postoperatorio[25], al igual que cirugías que no requieran de hospitalización prequirúrgica o de compensación de patologías de base.

Cirugías de mayor complejidad o que requieran unidades de apoyo, deben evaluarse según la condición local de cada centro y con un análisis multidisciplinario.

3.1.2. Estratificación de cirugías y pacientes a resolver por equipo multidisciplinario.

Considerar entre los factores para priorizar la atención del paciente pediátrico: el daño clínico colateral de postergar la resolución quirúrgica de su patología; si la resolución quirúrgica está asociada o no a prestaciones GES; el grado de discapacidad asociada en el paciente pediátrico; la opinión de los equipos médicos locales en relación a la atención quirúrgica del paciente pediátrico entre otros varios.

Contar con un comité de programación multidisciplinarios de procesos quirúrgicos según la organización local, con el fin de planificar y optimizar los recursos disponibles para ello.

\section{Criterios anestésicos}

Objetivo: Adecuada evaluación preoperatoria en contexto de pandemia COVID-19 y pesquisa oportuna de síntomas por infección de SARS-CoV-2.

\section{Recomendamos}

4.1. Evaluación preanestésica

Evaluación preanestésica no presencial (telefónica, videollamada, entre otras) por telemedicina posterior a la indicación quirúrgica, registrada en la ficha de paciente. Con fin de evitar el desplazamiento del paciente y su tutor al centro hospitalario[14],[18].

En ésta se requiere la presencia de un tutor responsable del paciente con fin de obtener datos médicos del paciente y explicar el acto anestésico, los riesgos asociados de la anestesia y la cirugía en tiempos de pandemia, normas de ayuno y aclarar dudas. Se debe educar en medidas de protección y prevención de contagio. 
Si existieran comorbilidades asociadas, deben estar compensadas y evaluadas por especialista en caso de ser necesario.

Aplicar nuevamente Lista de Chequeo (Anexo 1) al paciente y su núcleo familiar, con el fin de pesquisar tempranamente algún síntoma o condición asociada a pandemia por COVID-19.

\section{Test diagnósticos}

\section{Existen dos categorías de test actualmente dis- ponibles}

5.1. Detección de RNA viral SARS-CoV-2:

Corresponde a la amplificación del RNA viral usando reacción de polimerasas en cadena (PCR). Este test es el gold estandar para detectar la infección aguda por SARSCV-2[8],[16],[20].

La capacidad de detectar el virus depende de la técnica, tipo de muestra y realización en tiempo adecuado de la evolución de la enfermedad[20]. Es detectable hasta 1 día previo a los síntomas y declina a las 3 semanas[16].

5.2. Detección de la respuesta del huésped:

La respuesta del huésped se evalúa a través de los test serológico de anticuerpos IgM e IgG[17]. El nivel de anticuerpos depende de la respuesta inmunológica de cada individuo y van aumentando en el tiempo, observándose que la mayoría de los pacientes se convierten a partir del $7^{\circ}$ a $10^{\circ}$ día postcontagio. El test más sensible es el de anticuerpos totales y su aumento es acentuado entre la segunda y tercera semana postcontagio[16].

Su rol es muy importante en screening poblacional de infección por SARS-CoV-2, e identificación de personas que están inmunes y potencialmente protegidas[16]. La medición de anticuerpos no cumple un rol en el screening preoperatorio ni en la estratificación de riesgo perioperatorio[20].

5.3. Detección de SARS-CoV-2 preoperatorio. Recomendamos la toma de RT-PCR entre 24 y 48 h e incluso $72 \mathrm{~h}$ previo al procedimiento quirúrgico electivo[13],[14],[15],[16],[17],[18],[19],[20]. Es importante tener en cuenta que en los pacientes expuestos el 30\% son asintomáticos y el $56 \%$ es moderadamente asintomático y, por tanto, contagiantes[16].

\section{Screening personal de salud[15],[26]}

Objetivo: Realizar screening al personal de Salud para disminuir la propagación de la infección, mitigar la depleción de personal por cuarentenas innecesarias y proteger al personal de salud.

\section{Recomendamos}

Contar con cuestionario y control de temperatura diaria, sumado a test de laboratorio, para el personal de salud sintomático y asintomático. En este caso puede utilizarse RT-PCR o test de serológicos. La frecuencia y periodicidad del test a realizar será definido por la institución y protocolos locales.

\section{Requisitos para realización de la cirugía}

Objetivo: Evaluar antes de la cirugía los recursos locales de la institución, las condiciones epidemiológicas en la zona geográfica y conocer las medidas tomadas por las autoridades.

\section{Consideraciones [27]}

Estas recomendaciones son dinámicas, por lo que, las sugerencias deben adaptarse progresivamente, según los datos epidemiológicos nacionales diarios e indicaciones entregadas por MINSAL. Esta información debe ser utilizada a criterio de los equipos quirúrgicos pediátricos según la realidad de su centro hospitalario para la toma de decisiones de reinicio, mantención o suspensión de la cirugía electiva pediátrica.

Una vez que las condiciones epidemiológicas nacionales y las autoridades nacionales autoricen la cirugía electiva.

Tener una reducción sostenida de la tasa de nuevos casos COVID-19 en la zona, de al menos 14 días.

Disponibilidad de camas básicas y cupos en unidades críticas.

Acceso a Unidades de Apoyo (banco de sangre, rayos, anatomía patológica).

Disponibilidad de insumos y EPP.

Estas recomendaciones son dinámicas, por lo que las sugerencias deben adaptarse progresivamente según los datos epidemiológicos nacionales diarios e indicaciones entregadas por MINSAL. Esta información debe ser utilizada a criterio de los equipos quirúrgicos pediátricos según la realidad de su centro hospitalario para la toma de decisiones de reinicio, mantención o suspensión de la cirugía electiva pediátrica.

\section{Recomendamos}

6.1. Evaluar situación local:

Evaluar a nivel local y con equipo multidisciplinario, la posibilidad de inicio de la actividad quirúrgica electiva pediátrica[13],[27],[28],[29],[30], [31],[32],[33],[34]. Idealmente el Centro Hospitalario debiese encontrarse en Fase 0 o 1 (Tabla 


\section{Tabla 1. Fase COVID-19 del hospital a sistema de salud. Descripción de la condición de base[13]}

\begin{tabular}{ll}
\hline Fase & Descripción \\
0 & No hay pacientes COVID-19, el hospital funciona normalmente \\
I & Los pacientes COVID-19 están en el hospital, pero los recursos y camas/ventiladores mecánicos de la UCI no \\
están amenazados & $\begin{array}{l}\text { Muchos pacientes con COVID-19 están en el hospital, la disponibilidad de camas en la UCI/ventiladores mecá- } \\
\text { nicos es limitada y los recursos operativos y/o EPP son limitados }\end{array}$ \\
III & $\begin{array}{l}\text { Situación de crisis en la que la mayoría de los recursos de la UCI/ventiladores mecánicos se dirigen a pacientes } \\
\text { con COVID-19 y el quirófano y/o el equipo de EPP no están disponibles en forma mínima o total }\end{array}$
\end{tabular}

1)[13]

Considerar la posibilidad de suspender actividad quirúrgica pediátrica electiva en condiciones de insuficiente calidad en la atención de los pacientes quirúrgicos pediátricos o de insuficiente seguridad para el equipo de atención de salud[28],[32],[33],[35],[36].

Informar a los tutores del paciente pediátrico quirúrgico sobre los riesgos asociados a la atención de salud[13],[28],[31] y realizar un consentimiento específico, oportuno y adecuado, en tiempos de pandemia COVID-19 (Anexo 2).

Programar las cirugías, considerando mayores tiempos asignados a cada cirugía (colocación de EPP, aseo del pabellón).

6.2. Tránsito del paciente dentro del centro asistencial.

Se recomienda que el tránsito del paciente y su acompañante desde áreas prequirúgicas a pabellón y desde este a áreas postquirúrgicas sea por espacios exclusivos y libres de tránsito de pacientes COVID-19 (+). Esto incluye los pasillos, ascensores, áreas comunes, sala de espera y salas de hospitalización si corresponde. Estas áreas deben estar apropiadamente señalizadas. En caso de quiebre de estos estándares, la cirugía electiva debe pausarse hasta asegurar la desinfección de estos espacios.

6.3. Disponibilidad de personal e insumos.

Una planificación semanal flexible en conjunto con las autoridades locales, donde se evalúe la disponibilidad de camas, de personal, de insumos y unidades de apoyo (rayos, anatomía patológica)otros, para la planificación de cirugías o procedimientos electivos pediátricos.

Durante el reinicio de la actividad quirúrgica deben priorizarse cirugías que no requieran material especial.
Verificar la existencia de insumos y material quirúrgico el día previo a la cirugía, en forma presencial por el cirujano o representante del equipo quirúrgico autorizado.

Considerar la disponibilidad de cupo en unidad de Cuidados Intensivos, y acceso a hemoderivados, como parte fundamental en la programación quirúrgica electiva durante la pandemia.

Disponibilidad EPP para todo el personal involucrado en proceso quirúrgico. El tipo de EPP a utilizar dependerá del tipo y ubicación del procedimiento, y está basado en las recomendaciones nacionales de SACH[36]. Evaluar periódicamente el número y el tipo de elementos de protección personal disponibles, suficientes para programar cirugías y/o procedimientos electivos pediátricos en forma segura.

Considerar la posibilidad de suspender actividad quirúrgica electiva, por ausencia de seguridad para el equipo de atención de salud o de calidad en la atención de los pacientes quirúrgicos pediátricos.

Se sugiere que todo el equipo quirúrgico cumpla con las precauciones universales de la atención de salud, así como de aislamiento de contacto y gotitas con todos los pacientes quirúrgicos pediátricos.

6.4. Presencia a lo más de un acompañante exclusivo:

Con fines de seguridad en la atención del paciente, limitar el acompañamiento a lo más a una persona exclusiva durante toda la estadía hospitalaria.

Considerar en situaciones especiales la limitación de acceso de este acompañante en ciertas áreas de la atención, en las que se pueda aumentar el riesgo del proceso de atención de salud como, por ejemplo, la inducción anestésica, estadía en reanimador, entre otros. 
6.5. Consentimiento informado en contexto de pandemia.

Se debe entregar la información adecuada a los tutores del menor sobre los riesgos de la cirugía electiva durante la pandemia COVID-19 y solicitarles que firmen un consentimiento informado extraordinario especialmente para este fin. Una propuesta de consentimiento informado que debe ser validado por cada institución (Anexo 2).

\section{Realización de cirugía}

Objetivo: Dar a conocer algunas recomendaciones de la técnica anestésica y quirúrgica más adecuada en el contexto de pandemia COVID-19.

\section{Recomendamos}

7.1 Técnica anestésica.

La elección de la técnica anestésica va a depender del criterio anestesiológico y del tipo de cirugía a realizar, manejo multimodal del dolor[37] y prevención de náuseas y vómitos. Debe tenerse en cuenta que cualquier procedimiento que involucre el manejo de la vía aérea es generadora de aerosoles, por lo tanto, estos pacientes y el equipo de salud deberán manejarse utilizar EPP adecuados y máscaras N95 según las recomendaciones de la literatura internacional. y recomendaciones SACH[35],[36].

El número de personas debe limitarse en el pabellón.

Pese a que los pacientes tengan RT-PCR negativas, debe tenerse en cuenta que este resultado no es garantía de no infectabilidad, dado que este test presenta $30 \%$ de falsos negativos.

7.2. Técnica quirúrgica.

La elección de la técnica quirúrgica debe ser elegida según la experiencia del cirujano, teniendo en consideración el menor tiempo intraoperatorio y el menor tiempo de recuperación postoperatoria. Esto debe ser valorado caso a caso.

Es ideal iniciar el proceso con las cirugías más comunes que realiza el servicio de tal manera que todo el equipo pueda desenvolverse con rapidez y comodidad y evitar errores, dado que las medidas de protección COVID-19 agregan una carga importante a todo el personal.

7.3 Tipo de pabellón.

Las cirugías electivas deben realizarse en un pabellón asignado No-COVID-19 (donde solo se atiendan pacientes sin COVID-19 o sin sospecha de éste), que cumpla los requerimientos estándar para la realización del procedimiento.

Realizar el aseo del pabellón al finalizar cada intervención quirúrgica con solución de cloro $1.000 \mathrm{ppm}$ para pisos y muros, y aseo del mobiliario y equipamiento con alcohol al $70 \%[13]$.

\section{Período postoperatorio}

Objetivo: Mantener los cuidados postoperatorios y entregar la mayor protección posible a los pacientes y al equipo de salud, considerando que hay pacientes pediátricos asintomáticos COVID-19(+).

\section{Recomendamos}

8.1. Traslado de pabellón a recuperación:

Trasladar al paciente de pabellón a recuperación cuando éste tenga un control seguro de la vía aérea, sin agitación.

El traslado del paciente a recuperación por un flujo de tránsito distinto al de pacientes COVID-19 (+).

El traslado del paciente debe ser realizado por personal de salud con EPP correspondiente y el paciente con uso de mascarilla quirúrgica debe ser realizado con EPP y mascarilla quirúrgica (para el paciente mayor de 2 años).

$\mathrm{Si}$ el paciente requiere aporte de oxígeno, debe ser trasladado con naricera a flujos $<3$ lit/min y sobre ésta, la mascarilla quirúrgica desde el pabellón[38].

8.2. Estadía en recuperación:

Se debe contar con el mínimo de personal posible que mantenga el adecuado cuidado de los pacientes pediátricos. Idealmente, mantener solo un paciente a la vez en sala de recuperación.

La organización y disposición de camas debe planificarse pensando en la prevención de contacto por gotitas, por eso se sugiere una separación mayor a 2 metros y delimitar los espacios en forma visible en el suelo.

El equipamiento de protección personal de los funcionarios en recuperación postanestésica debe basarse en la prevención de infección por contacto y gotitas, es decir, incluir mascarilla quirúrgica, protección ocular, guantes y pechera[35],[36].

La mascarilla quirúrgica instalada en pabellón al paciente debe mantenerse en su posición durante toda la recuperación si es que el niño 
lo tolera.

La monitorización debe ser la estándar según las medidas de cada centro.

Recomendamos la ausencia de tutor del menor en sala de recuperación. Una excepción a esta recomendación podría ser niños con necesidades especiales, quienes podrían ser acompañados solo por un tutor, el cual debe utilizar mascarilla quirúrgica, realizar lavado de manos al ingreso a recuperación y no le está permitido deambular.

El tiempo en recuperación debe ser el mínimo necesario para cumplir con los criterios de alta.

En caso de necesitar algún broncodilatador evitar nebulizaciones[38].

8.3. De recuperación a sala o habitación:

La salida de la sala de recuperación a su pieza de hospitalización, debe ser por un flujo de tránsito distinto al de pacientes COVID-19 (+). El paciente debe utilizar la mascarilla quirúrgica que se utilizó desde la salida del pabellón, si lo tolera.

8.4. Manejo postoperatorio en sala y criterios de alta y seguimiento:

El manejo postoperatorio es muy importante en la cadena de atención, y se deben mantener las medidas de prevención ya descritas. Es por esto, que se han definido una serie de sugerencias para implementar en el postoperatorio inmediato, al alta y durante el seguimiento.

8.4.1. Recomendaciones para manejo postoperatorio inmediato:

La estadía postoperatoria en la habitación debería realizarse en sectores libres de COVID-19 $(+)$.
Evaluar según la edad y condiciones del niño, que complete su postoperatorio asegurando el uso de mascarilla en todo momento y lavado de manos frecuente para el acompañante del menor.

El acompañante del menor deberá permanecer en la sala asignada al paciente para evitar aglomeraciones en la sala de espera, velando mantener distancia mayor de un metro con otros pacientes o tutores idealmente.

Planificar el perioperatorio con el objetivo de minimizar la estadía hospitalaria postoperatoria. Esto incluye: restricción de fluidos en el postoperatorio, realimentación precoz y traslape a medicación oral lo antes posible. Estos principios están contenidos en lo que se conoce como protocolos "ERAS" pediátricos[39].

8.4.2. Sugerencias para el alta y seguimiento.

El paciente debe cumplir con las condiciones de alta según protocolo de cirugía ambulatoria local.

Los controles ambulatorios puedan realizarse en forma presencial, por telemedicina o por teléfono dentro de los 5-10 días de la cirugía[13].

En cada control debe evaluarse la presencia de los síntomas respiratorios y gastrointestinales como vigilancia epidemiológica de COVID-19, tanto para el menor que se operó como también para todos los que viven bajo el mismo techo. En caso que la encuesta resulte positiva y es una consulta presencial se debe seguir los protocolos locales de EPP, aislamiento y toma de RT-PCR, según corresponda, y si resultara positivo por telemedicina o teléfono, dirigirlos a consultar en atención primaria para realización del screening. 


\section{Referencias}

1. Gobierno reactiva garantía de oportunidad AUGE suspendidas por COVID-19 y autoriza cirugías ambulatorias. Disponible en: https://www.minsal.cl/ gobierno-reactiva-garantia-deoportunidad-auge-suspendidaspor-covid-19-y-autoriza-cirugiasambulatorias/

2. Lazzerini M, Barbi E, Apicella A, et al. Delayed access or provision of care in Italy resulting from fear of COVID-19. The Lancet Child \& Adolescent Health. 2020 vol:4, Issue 5: e10-e11. https://doi.org/10.1016/S23524642(20)30108-5

3. Sun D, Li H, Lu XX, et al. Clinical features of severe pediatric patients with coronavirus disease 2019 in Wuhan: a single center's observational study [published online ahead of print, 2020 Mar 19]. World J Pediatr. 2020;1-9. https://doi.org/10.1007/s12519020-00354-4

4. Cruz AT, Zeichner SL. COVID-19 in Children: Initial Characterization of the Pediatric Disease [published online ahead of print, 2020 Mar 16]. Pediatrics. 2020;e20200834. https://doi. org/10.1542/peds.2020-0834

5. Nuevo Coronavirus (COVID-19) en población general y pediátrica: una revisión epidemiológica. Chile 2020. Revista Chilena de Neumología Pediátrica.2020;15(2):293-300. Disponible en: https://www. neumologia-pediatrica.cl

6. PICS Statement: Increased number of reported cases of novel presentation of multisystem inflammatory disease. 27 april 2020. Disponible en: https://picsociety.uk/news/ pics-statement-regarding-novelpresentation-of-multi-systeminflammatory-disease/

7. Manejo del paciente pediátrico ante sospecha de infección por el nuevo coronavirus SARSCoV-2 en atención primaria (COVID-19). AEPap-SEIP/AEPSEPEAP. Disponible en: https:// www.aepap.org/sites/default/ files/noticia/archivos-adjuntos/2020_04_07_covid_ap.pdf

8. Informe Epidemiólogico N³119 Enfermedad por SARS-Covid-2 (COVID-19). Chile 522-75-2020. Departamento de Epidemiología. Disponible en: https://www.gob. cl/coronavirus/cifrasoficiales/

9. Aminian A, Safari S, RazeghianJahromi A, et al. COVID-19 Outbreak and Surgical Practice: Unexpected Fatality in Perioperative Period. Annals of Surgery. March 26, 2020. https://doi.org/10.1097/ SLA.0000000000003925

10. Zhou Y, Xu H, Li L, et al. Management for patients with pediatric surgical disease during the COVID-19 epidemic. Pediatric Surgery International.2020. https://doi.org/10.1007/s00383020-04656-6

11. CDC COVID-19 Response Team. Coronavirus Disease 2019 in Children - United Sattes, Febrauary 12-April 2, 2020. MMWR Morb Moratl Wkly Rep. 2020; 69(14):422-426. Published 2020 apr 10. https://doi. org/10.15585/mmwr.mm6914e4

12. Actualización de definición de caso sospechoso para vigilancia epidemiológica ante brote de COVID-19. 23 marzo 2020. Disponible en: https://www.minsal. cl/wp-content/uploads/2020/04/ Ord.-B51-N933.pdf

13. Recomendaciones para iniciar o aumentar la actividad quirúrgica electiva durante la pandemia COVID-19 en los hospitales públicos de Chile. Sociedad de Anestesiología de Chile. Disponible en: https://www. sachile.cl/upfiles/userfile/files/ Recomendaciones-SACH-para- iniciar-o-aumentar-la-actividadquirurgica-electiva-durante-lapandemia-COVID-19-V04.pdf

14. Recommandations de Pratiques Professionnelles - Préconisations pour l'adaptation de l'offre de soins en anesthésie-réanimation dans le contexte de pandémie de COVID-19. Version Mai 2020. Disponible en: https://sfar.org/ download/recommandationsde-pratiques-professionnellespreconisations-pour-ladaptationde-loffre-de-soins-en-anesthesiereanimation-dans-le-contextede-pandemie-de-covid-19-version-mai-2020/?wpdmdl=26 224\&refresh $=5$ ed $13424 \mathrm{c} 16$ 8e1590768676

15. Hanson K, Caliendo A, Arias $C$, et al. Infections Diseases Society of America Guidelines on the Diagnosis of COVID-19. Publicado por Infectious Diseases Society of America. IDSA 6 mayo 2020. Diponible en: https:// www.idsociety.org/globalassets/ idsa/practice-guidelines/covid-19/ diagnostics/idsa-covid-19-guideline_dx_version-1.0.1.pdf

16. Sethuraman N, Jeremiah SS, Ryo A. Interpreting Diagnostic Test for SARS-CoV-2. JAMA. Published online May 06, 2020. https://doi.org/10.1001/ jama.2020.8259

17. Al-Muharraqi MA. Testing recommendation fro COVID-19 (SARAS-CoV-2) in patients planned for surgery - continuing the service and 'suppresing' the pandemic. Br J Oral Maxillofac Surg. 2020; S0266-4356(20)301649. https://doi.org/10.1016/j. bjoms.2020.04.014

18. COVID-19 - Elective Surgical Procedure Guidance. Illinois Department of Publkic Health. Disponible en: https://www. dph.illinois.gov/topics-services/ diseases-and-conditions/diseasesa-z-list/coronavirus/health-careproviders/elective-procedures- 
guidance

19. Society for Ambulatory

Anesthesia (SAMBA) Statement on COVID-19 Testing Before

Ambulatory Anesthesia. 30 april 2020. Disponible en: Society for Ambulatory Anesthesia (SAMBA) Statement on COVID-19 Testing Before Ambulatory Anesthesia 4/30/2020

20. ASA and APSF Joint Statement on perioperative Testing for the COVID-19 virus, Anesthesia Patient Foundation. https:// www.apsf.org/news-updates/ asa-and-apsf-joint-statementon-perioperative-testing-for-thecovid-19-virus/

21. Prachand $V$, Milner $R$, Angelos $P$, et al. Medically Necessary, Time-Sensitive Procedures: Scoring System to Ethically and Efficiently Manage Resource Scarcity and Provider Risk During the COVID-19 Pandemic. Journal of American College of Surgeons. 2020; 0:1-8. https:// doi.org/10.1016/j.jamcollsurg.2020.04.011

22. American College of Surgeons. COVID-19: Elective Case Triage Guidelines for Surgical Care. Pediatric Surgery. March 24, 2020. Disponible en: https://www.facs. org/covid-19/clinical-guidance/ elective-case/pediatric-surgery

23. Slidell M, Kandel J, Prachand $\mathrm{V}$, et al. Pediatric Modification of the Medically Necessary, Time - Sensitive Scoring System for Operating Room Procedure Priorization During the COVID-19 Pandemic. Journal of the American College of Surgeons. 2020. https://doi.org/10.1016/j. jamcollsurg.2020.05.015

24. Management for patients with pediatric surgical disease during the COVID-19 epidemic, Yan Zhou, Hang Xu, Long Li, Xianghai Ren, Pediatric Surgery International. https:// doi.org/10.1007/s00383-020-
04656-6

25. Rajan N, Joshi G. The COVID19:Role of Ambulatory Surgery Facilities in This Global Pandemic. Anesth Analg. 2020 https://doi.org/10.1213/ ANE.0000000000004847

26. Black J, Baily C, Przewrocka J. COVID-19: the case for health-care worker screening to prevent hospital transmission. The Lancet. 2020.Vol 395, Issue 10234:1418-1420. https://doi.org/10.1016/S01406736(20)30917-X

27. Joint Statement: Roadmap for Resuming Elective Surgery after COVID-19 Pandemic. April 17, 2020. https://www.facs.org/ covid-19/clinical-guidance/roadmap-elective-surgery

28. Lee-Archer P, Von Ungern-Sternberg B. Pediatric anesthetic implications of COVID-19-A review of current literature. Pediatric Anesthesia. 2020;00:1-6. https:// doi.org/10.1111/pan.13889

29. Pediatric Elective Surgery/Procedure Guidance, The Children's Hospital Association, United States, March 23, 2020. Disponible en: https://www.mnhospitals.org/Portals/0/Documents/ patientsafety/Emergency_Preparedness/CHA\%20Pediatric\%20 Elective\%20Surgery\%20Guidance\%20March\%2023\%202020. pdf

30. Quaedackers JSLT, Stein R, Bhatt $\mathrm{N}$, et al. Clinical and surgical consequences of the COVID-19 pandemic for patients with pediatric urological problems: Statement of the EAU guidelines panel for paediatric urology, March 30 2020 [published online ahead of print, 2020 Apr 9]. J Pediatr Urol. 2020;S1477-5131(20)301054. https://doi.org/10.1016/j. jpurol.2020.04.007

31. Stahel Ph. How to risk-stratify elective surgery during the COVID-19 pandemic?. Patient
Safety in Surgery. 2020; 14:8. https://doi.org/10.1186/s13037020-00235-9

32. Recomendaciones para Manejo de Paciente Quirúrgico con COVID-19 +. Sociedad Chilena de Cirugía Pediátrica, 1 abril 2020. Disponible en: https:// www.schcp.cl/2020/04/04/ recomendaciones-para-manejopaciente-quirurgico-covid-19/

33. Guidance for Pediatric Patient Care Reengagement, The Children's Hospital Association United States, 1 mayo 2020. Disponible en : https://www. childrenshospitals.org/Qualityand-Performance/COVID19/Resources/Guidance-for-PediatricPatient-Care-Reengagement

34. Smith ER, Concepción T, Lim $S$, et al. Disability Weights for Pediatric Surgical Procedures: A Systematic Review and Analysis. World J Surg 42, 3021-3034 (2018). https://doi.org/10.1007/ s00268-018-4537-6

35. Lockhart SL, Duggan LV, Wax $\mathrm{RS}$, et al. Personal protective equipment (PPE) for both anesthesiologists and other airway managers: principles and practice during the COVID-19 pandemic. Can J Anesth/J Can Anesth. 2020. https:// doi.org/10.1007/s12630-02001673-w

36. Recomendaciones de Precauciones para el control de infecciones de Anestesiólogos durante COVID-19. Comité Científico Sociedad de Anestesiología de Chile. https://www.sachile.cl

37. Campos T, Eulufi S, Fajardo M, et al. Recomendación Clínica "Manejo del Dolor Aguos Perioperatorio en Niños". Rev Chil Anest. 2018. Vol 47 (1):46-63. https://doi.org/10.25237/revchilanestv47n01.09

38. Bernucci M, Fajardo A, Maureira $V$, et al. Anestesia para pacientes pediátricos con COVID-19. 
Revista Chilena de Anesestesia. 2020; 49:422-432. https:// doi.org/10.25237/revchilanestv49n03.022
39. Shinnick JK, Short HL, Heiss $\mathrm{KF}$, Santore MT, Blakely ML, Raval MV. Enhancing recovery in pediatric surgery: a review of the literature. J Surg Res. 2016;202(1):165-176. https://doi.org/10.1016/j. jss.2015.12.051 